J. clin. Path., 1970, 23, 47-53

\title{
An automated method for the measurement of folate activity
}

R. E. DAVIS, D. J. NICOL, AND A. KELLY

From the Department of Haematology, Royal Perth Hospital, Perth, Western Australia

SYNOPSIS A new approach to the estimation of folate activity is described. The system may $\vec{T}$ be used as a semi-automated method or as a fully automated method using the AutoAnalyzer or Mecolab equipment. The methods use a chloramphenicol-resistant strain of $L$. case $i$ as the test organism, and this eliminates the need for sterilization or aseptic addition. The systems are able to handle extremely large numbers of samples in a relatively short time. Results are similar to those obtained by standard techniques.

The techniques described for the measurement of folate activity are essentially similar (Baker, Herbert, Frank, Pasher, Hutner, Wasserman, and Sobotka, 1959; Herbert, 1961 ; Waters and Mollin, 1961 ; Davis and Kelly, 1962). They are all somewhat tedious, demanding careful attention to detail, and are time consuming. For these reasons they are suitable for the assay of small or moderate numbers of sampics in a batch, but are not easily adarted to handle the large numbers involved in some surveys.

Herbert in 1966 described an 'aseptic' addition assay technique which eliminated pretreatment of the serum and reduced the numbers of manipulations, thus simplifying the technique considerably. However, it still has many of the drawbacks of the earlier methods.

This paper describes a new approach to the Received for publication 11 September 1968. estimation of folate activity using either a semi- 을 automatic system requiring little specialized $D$ equipment, or alternatively, a fully automated system designed for use with the Technicon $N$ AutoAnalyzer or Joyce Loebl Mecolab systems. Each system has a very large capacity, is simple to set up and operate, and gives highly reproducible results.

\section{Methods and Materials}

PREPARATION OF THE TEST ORGANISM

A chloramphenicol-resistant strain of Lactobacillus casei was developed from the original ATCC 7469 strain. The organism was serially subcultured into liquid maintenance medium N 


\begin{tabular}{|c|c|c|c|c|c|c|c|c|}
\hline & \multicolumn{8}{|c|}{ Tube No. } \\
\hline & 1 & 2 & 3 & 4 & 5 & 6 & 7 & 8 \\
\hline \multirow{3}{*}{$\begin{array}{l}\text { Folate solution }(150 \mathrm{ng} / \mathrm{ml})-\mathrm{ml} \\
\text { Water } \\
\text { Folate concentration }(\mathrm{ng} / \mathrm{ml}) \\
\text { Final concentration after dilution with } \\
\text { substrate }(\mathrm{ng} / \mathrm{ml})\end{array}$} & 0.5 & $1 \cdot 0$ & $2 \cdot 0$ & $\begin{array}{r}4 \cdot 0 \\
\text { to }\end{array}$ & $\begin{array}{l}6 \cdot 0 \\
\mathrm{nl}\end{array}$ & $8 \cdot 0$ & $10 \cdot 0$ & $12 \cdot 0$ \\
\hline & $0 \cdot 75$ & $1 \cdot 5$ & $3 \cdot 0$ & $6 \cdot 0$ & $9 \cdot 0$ & $12 \cdot 0$ & $15 \cdot 0$ & $18 \cdot 0$ \\
\hline & $000 \cdot 75$ & 0.015 & 0.03 & 0.06 & 0.09 & $0 \cdot 12$ & $0 \cdot 15$ & $0 \cdot 18$ \\
\hline
\end{tabular}

Table I Preparation of working solutions for standard curve

containing increasing concentrations of chloramphenicol base ${ }^{1}$, starting at a level of $1 \mu \mathrm{g} / \mathrm{ml}$ and reaching a final concentration of $10 \mu \mathrm{g} / \mathrm{ml}$. Higher concentrations of the antibiotic may be used, but above $50 \mu \mathrm{g} / \mathrm{ml}$ growth was retarded compared with the growth of the standard strain. In developing antibiotic resistance it was found that an occasional tube showed poor growth. When this occurred, the organism was subcultured back into a tube of medium containing the same concentration of antibiotic as that to which the organism had previously been exposed, and this was repeated if necessary until good growth occurred. It was found that $L$. casei readily developed a resistance to chloramphenicol under these conditions.

Stock cultures were stored as a liquid culture at $4{ }^{\circ} \mathrm{C}$ using the medium described by Herbert (1966) with chloramphenicol added to a concentration of $10 \mu \mathrm{g} / \mathrm{ml}$.

On the evening before the test, the organism was subcultured into a fresh tube of maintenance media and incubated at $37^{\circ} \mathrm{C}$ overnight. This overnight culture was used as the inoculum.

\section{SERUM SAMPLES}

Blood was collected from fasting subjects into disposable glass vials. The serum was separated and stored in glass vials at $-20^{\circ} \mathrm{C}$ until required.

RED CELLS

Venous blood was collected into plastic vials containing dry dipotassium ethylene-diamine tetra acetate. As soon after the collection as possible $0.5 \mathrm{ml}$ of packed cells was added slowly to $4.5 \mathrm{ml}$ of $1 \%$ freshly prepared ascorbic acid. The resulting haemolysate was stored at $-20^{\circ} \mathrm{C}$ until required (Hoffbrand, Newcombe, and Mollin, 1966).

STANDARD FOLIC ACID SOLUTIONS A stock solution was prepared by taking $1 \mathrm{ml}$ of sodium folate (Lederle) containing $15 \mathrm{mg}$ pteroylglutamic acid and diluting this to $100 \mathrm{ml}$ with distilled water. This solution keeps for months if stored in the dark at $4{ }^{\circ} \mathrm{C}$. On the morning of the test the stock solution ivas further diluted $1: 1,000$ giving a concentration of $150 \mathrm{ng}$ per $\mathrm{ml}$. ${ }^{1}$ Parke Davis.
This working solution was used to prepare the final standard solutions as shown in the protocyl (Table I) and these were sampled in the same manner as the serum or other material to be assayed.

\section{GLASSWARE}

For the semi-automated method disposalge 4 in. $\times \frac{5}{8}$ in. glass test tubes were used ${ }^{1}$, and fer the fully automated method using discreffe analysis, 3 in. $\times \frac{5}{8}$ in. tubes ${ }^{2}$. They were purchased in batches of 100 gross and samples from sevenal boxes were tested for their ability to enhance $\overline{\text { gr }}$ suppress growth of the test organism under standard conditions. If the tubes failed to influence growth, they were used without washing or amy ${ }^{1}$ H. B. Selby and Co. Ltd, $\$ 2 \cdot 09$ a gross, based on 100 gross ${ }^{2} \mathrm{C}$. E. Payne, London, $10 \mathrm{~s} 9 \mathrm{~d}$ a gross, based on 100 gross lot?

\begin{tabular}{|c|c|c|c|c|c|c|c|}
\hline \multicolumn{4}{|c|}{ Enzymatic casein hydrolysate (NBC) } & . & . & . & 800 \\
\hline Glucose . . & $\ldots$ & & . & . & . & . & $160 \cdot 0$ \\
\hline \multicolumn{3}{|c|}{$\mathrm{Na}$ Acetate (anhydrous) } & . . & . & . & . & $160 \cdot 0$ \\
\hline L-asparagine & . & . . & . & . & . & . & $2 \cdot 4$ \\
\hline L-cysteine $\mathrm{HCl}$ & . & . & . & . & . & . & \\
\hline L-tryptophan & . & . & . & . & . & . & \\
\hline $\mathrm{K}_{2} \mathrm{PO}_{4} \quad \ldots$ & . & . & . & . & . & . & \\
\hline $\mathrm{KH}_{2} \mathrm{PO}_{4} \quad \ldots$ & . & . & . & . & . & . & \\
\hline Dl.-alanine & . & .. & . & . & . & . & $1 \cdot 6$ \\
\hline Glutathione ( red & duced) & .. & $\ldots$ & . & . & . & 20 \\
\hline Adenine $^{1} \ldots$ & .. & . & $\ldots$ & . . & . & . . & 40 \\
\hline Guanine $\mathrm{HCl}^{1}$ & $\ldots$ & .. & . & . & . & . . & 40 \\
\hline Xanthine ${ }^{1}$.. & $\cdots$ & $\cdots$ & $\cdots$ & $\cdots$ & . & . & 80 \\
\hline Uracil $^{1} \quad \ldots$ & $\ldots$ & . & . & . & . & . & 40 \\
\hline p-Aminobenzoic & acid & . & . & . & . & . & 8 \\
\hline Ca pantothenate & . & . & . & . & . & . & $3 \cdot 2$ \\
\hline Nicotinic acid & . & . & $\ldots$ & . & . & . & $3 \cdot 2$ \\
\hline Pyridoxine $\mathrm{HCl}$ & . & . & . & . & . & . & 16 \\
\hline Thiamine $\mathrm{HCl}$ & $\ldots$ & . . & $\ldots$ & . & . & . & $1 \cdot 6$ \\
\hline Riboflavin & . & . & . & . & . & . & 4 \\
\hline Biotin $(10 \mu \mathrm{g} / \mathrm{ml})$ & . & . & . & . & . & . & 8 \\
\hline Salt solution $\mathbf{B}^{2}$ & . & . & . & . & . & & 40 \\
\hline Tween $80(1: 10$ & 0 diluti & on) & . & . & . & $\ldots$ & 4 \\
\hline Distilled water & $\cdots$ & . & $\cdots$ & . & . & . & to 41 \\
\hline
\end{tabular}

Adjust $p \mathrm{H}$ to 6.8 then add 0.8 of $\mathrm{MnSO}_{4} \cdot \mathrm{H}_{2} \mathrm{O}$, filter, and store dark at $20 \mathrm{C}$.

${ }^{1}$ Dissolved by suspending in a small volume of $\mathrm{H}_{2} \mathrm{O}$ and the adding concent rated $\mathrm{KOH}$ drop by drop until solution is complepe.

${ }^{2}$ Salt solution B. $(\mathrm{MgSO}_{4}, 5 \mathrm{H}_{2} \mathrm{O}, 10 \mathrm{~g}, \mathrm{NaCl}, 0.5 \mathrm{~g}, \mathrm{MnSO}_{4} \underbrace{\Phi}$, $0.5 \mathrm{mg}$ in distilled water to $250 \mathrm{ml}$ ).

Immediately before the test add to each litre of single-strengh medium $0.15 \mathrm{~g}$ ascorbic acid and $10.0 \mathrm{ml}$ chloramphento $(1 \mathrm{mg} / \mathrm{ml})$. 


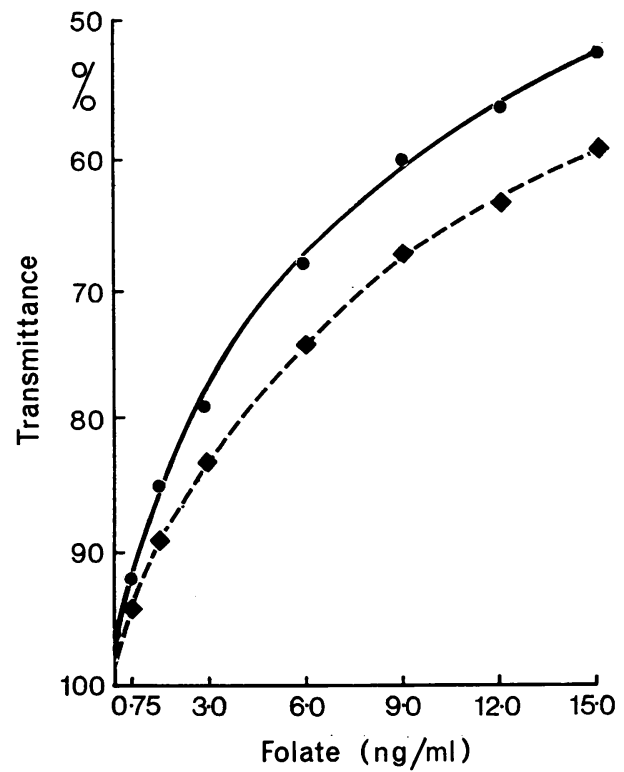

Fig. 1 Comparison of growth curves using media containing hydrolysed casein (- $\longrightarrow$ ) and acid hydrolysed casein (- - -).

treatment other than sterilization in the hot air oven at $170^{\circ} \mathrm{C}$ for one hour.

One 1-litre and eight 100-ml volumetric flasks, and one $1-\mathrm{ml}$ and one $10-\mathrm{ml}$ graduated pipettes were used for the preparation of the standards. This glassware was cleaned initially by washing in detergent, rinsed several times in tap water, followed by soaking in $1 \% \mathrm{HCl}$. After rinsing several times in distilled water, the glassware was filled with glass-distilled water and autoclaved. This was repeated three times. The glassware was retained exclusively for the preparation of folate standards and subsequently only required rinsing with glass-distilled water after use.

\section{SUBSTRATE}

Double-strength assay medium was prepared as described in Table II, and stored at $-20^{\circ} \mathrm{C}$ until required. For the assay, $500 \mathrm{ml}$ of medium was mixed with an equal volume of distilled water containing $150 \mathrm{mg}$ of ascorbic acid and $10 \mathrm{mg}$ of chloramphenicol base. Fast thawing of the medium was achieved by autoclaving at $10 \mathrm{lb}$ pressure for two minutes. Growth obtained with heated medium did not differ from slowly thawed medium. The solution was thoroughly mixed using a magnetic stirrer, and inoculated with $0.1 \mathrm{ml}$ of an overnight culture of the test organism.

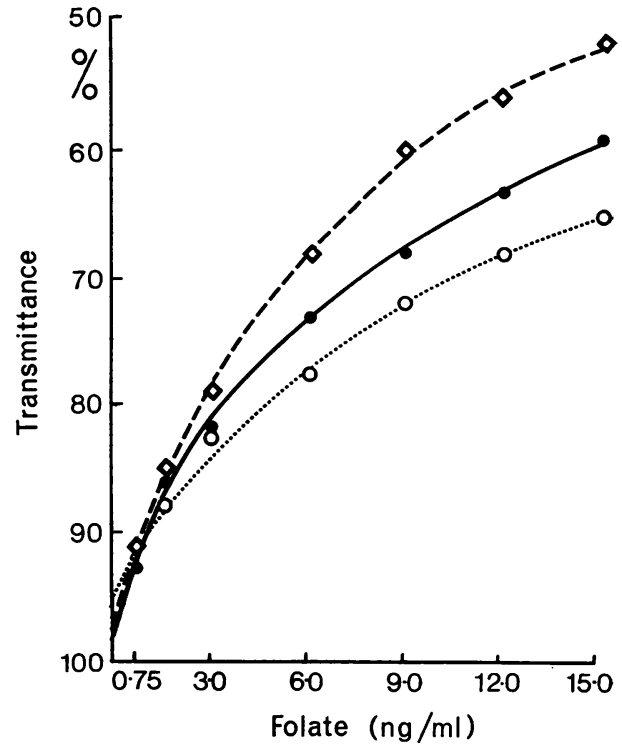

Fig. 2 Comparison of growth curves obtained with Cooperman's media with (- $\longrightarrow$ ) and without (. . . .) added Tween 80 and the standard medium (- - - ).

The use of enzymatic casein hydrolysate as described by Waters and Mollin (1961) in place of the original acid hydrolysed material considerably enhanced growth of the test organisms (Fig. 1) and at the same time gave reduced growth in the blank tube.

The basal medium recently described by Cooperman (1967) was compared with our standard medium. Cooperman did not recommend the addition of Tween 80 to his medium, and without this, growth occurred in globules and was generally poor. With added Tween 80 , growth improved, and was equivalent to our standard medium using acid hydrolysed casein (Fig. 2); however, growth was still inferior to that obtained with our standard medium prepared with enzymatic casein hydrolysate, and this medium was retained for the test. These differences are probably due to changes in the characteristics of the organism after many years of serial subculture.

\section{Semi-automated Technique}

An autodilutor was used to sample the serum or other material to be assayed and deliver it, plus $10 \mathrm{ml}$ of inoculated substrate, into a tube. The 
tubes were closed with disposable plastic caps ${ }^{1}$ and incubated at $37^{\circ} \mathrm{C}$ for 20 hours after which growth was measured in a colorimeter.

A Trimatic dispenser ${ }^{2}$ or similar dilutor was adjusted to sample $0 \cdot 1 \mathrm{ml}$ and to dilute to $10 \mathrm{ml}$. The pipette was treated with silicone ${ }^{3}$ to reduce sample carry over. Before and immediately after use the dilutor was thoroughly washed through with distilled water.

The inoculated substrate was stirred continuously with a magnetic stirrer, and, if the setting up time exceeded 30 minutes, it was cooled to approximately $10^{\circ} \mathrm{C}$. Serum or other samples were diluted with the inoculated substrate and delivered into a disposable tube. All tests were set up in duplicate. The standard solutions were sampled in the same manner beginning with the most dilute solutions. The tubes were closed with disposable plastic caps then incubated at $37^{\circ} \mathrm{C}$ for 20 hours; an inoculated blank was included in each batch.

After mixing by inversion, growth was measured in a colorimeter ${ }^{4}$ fitted with a flow cell. All readings were made using an Ilford 622 bright spectrum blue filter. The instrument was adjusted to zero using the inoculated blank and the growth of the samples and standards measured as percentage transmission. A standard curve was plotted as shown in Figure 3.

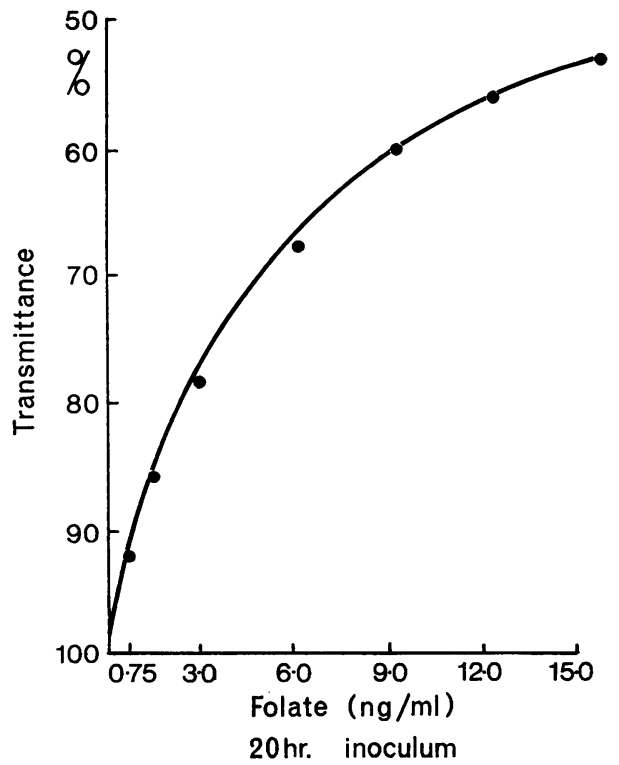

Fig. 3 Standard curve obtained using the autodilutor for setting up.
Techniques Using the Autoanalyzer

Serum samples were diluted 1 in 10 with distille water, using an autodilutor before being placed in the analyzer. This conserved serum and substrate, and reduced the cost of the test. T势e inoculated substrate is prepared in the manner described for the autodilutor method. The standards, prepared as previously described, we्gre diluted in the same manner as the serum samp席.

MANIFOLD DESIGN

क

An incubation coil was made by winding $210-\mathrm{ft}$ of polythene tubing having an internal diameger of $2.8 \mathrm{~mm}^{5}$ on to a plastic cylinder (Fig. 4). The tube was held in place with Araldite. The eñds of the tube were fitted with Luer adaptors anda plastic three-way stockcock ${ }^{6}$ previously drilted out to increase the bore. The analyzer modufes were assembled as shown in the flow diagrom (Fig. 5) and the coil was filled. Once full, the taps were closed, the coil was removed from the system and incubated at $37^{\circ} \mathrm{C}$ for 20 hous. On completion of the incubation, the coil as

${ }^{1}$ A.C.I. Plastic, Kingsway, N.S.W.

${ }^{2}$ Research Specialitics.

${ }^{3}$ Clay Adams Siliclad.

"Unicam SP 1300.

'Portex, Boots Pty Ltd.

-Pharmaseal K75.

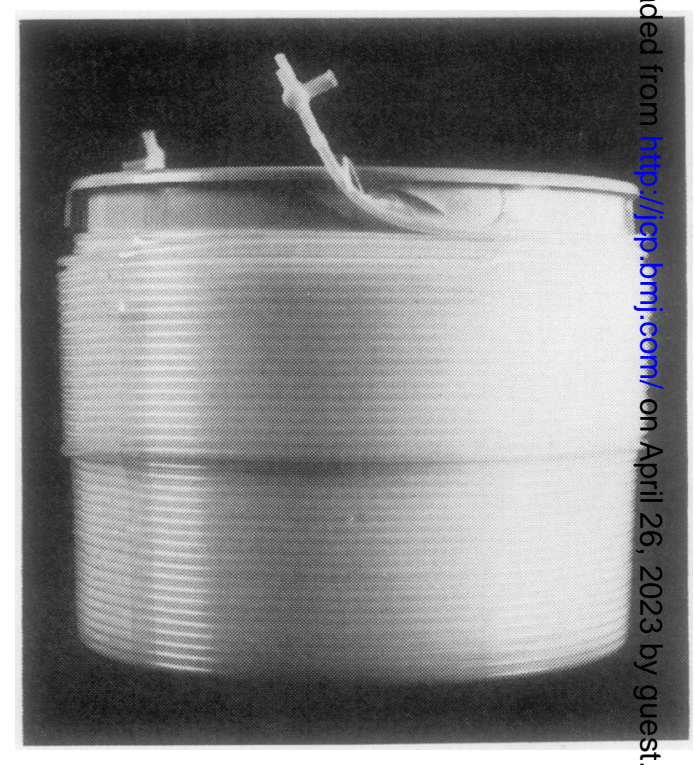


FLOW RATES $(\mathrm{mL} / \mathrm{min})$

I. SAMPle ..........0.32.

2. SUbSTRATE ........3.9.

3. AIR $\ldots \ldots \ldots \ldots \ldots 1 \cdot 6$.

4. WATER WASH .........2.0.

5. COLORIMETER MASTE ...2.0.

6. COLORIMETER WASTE ... 3.4

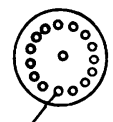

returned to the analyzer, and the coil contents were pumped through the colorimeter and the growth measured (Fig. 6). Each coil holds 40 samples, ie, the same number as the sample plate. Any number of coils can be fabricated depending on particular requirements.

\section{Technique Using the Mecolab System}

This instrument has been modified to enable it to handle large numbers of samples. The sample plate will hold 40 serum samples and 40 sample tubes. The inner ring of sample tubes after filling are removed in their rack and incubated. The rings are designed for stacking. By placing a new ring of sample tubes within the specimen disc, tests can be set up in duplicate or triplicate as required. The instrument is also able to set up the tests at four different preset dilutions and this is a useful facility when checking for the presence of inhibitors. The system can set up 200 tests per hour and uses $5 \mathrm{ml}$ volumes of substrate.

Fig. 5 Flow diagram and manifold design for the AutoAnalyzer.

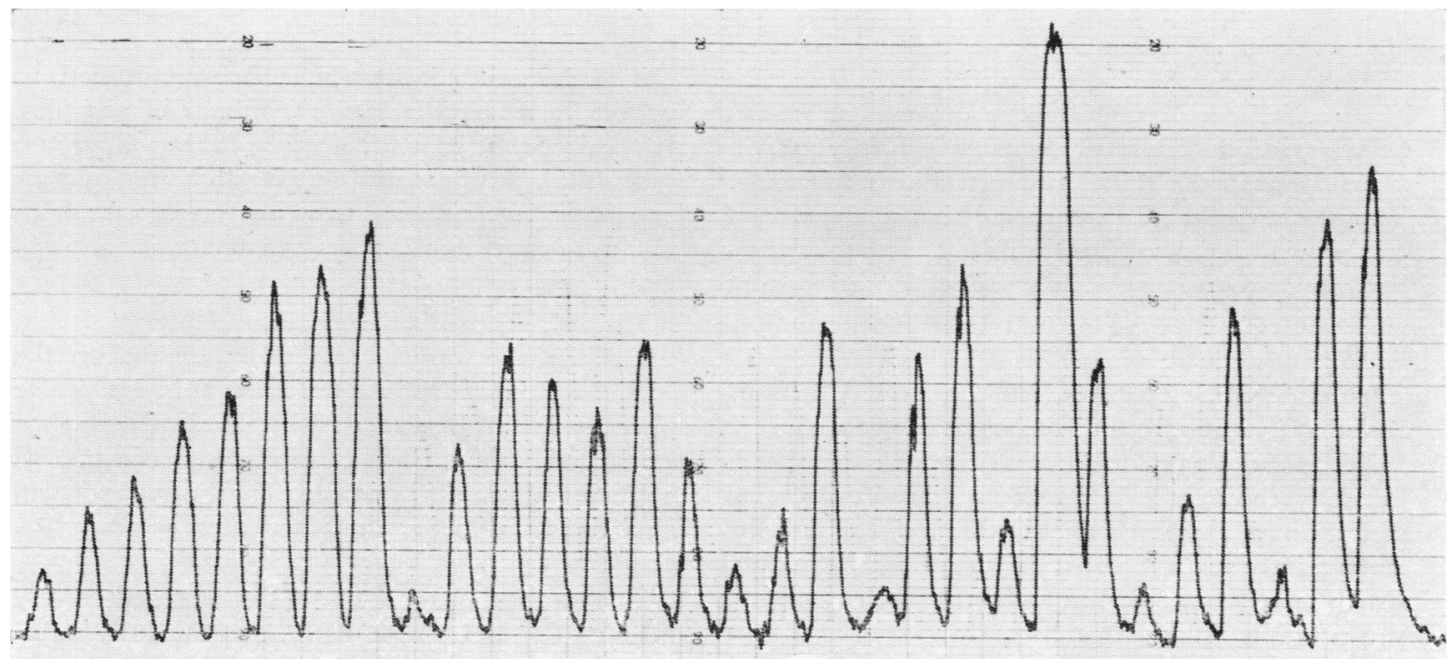

Fig. 6 Graph showing results from the AutoAnalyzer: from the left the first eight peaks represent the standard curve 1, 2, 3, 4, 6, 9, 12, and $15 \mathrm{ng} / \mathrm{ml}$; the remaining peaks are from test serum samples. 
After incubation, they are placed in the reading section of the instrument where they are mixed and read. The time between mixing and reading is constant, and the colorimeter is of a type particularly well suited to measuring bacterial turbidity. Results are passed to an analogue digital converter which operates a printout unit. The printout unit also records a serial number and batch number, and should the sample fall outside the range of the colorimeter the instrument indicates this in red print.

\section{Results}

Duplicate blood samples were collected from 58 healthy volunteers. The duplicate samples were assayed by both the standard and the autodilution methods to determine the internal precision of each technique. The 116 results obtained by each method were then compared. The paired samples were then labelled $A$ and $B$. By the standard method the $A$ mean was 6.6 and the $B$ mean $7 \cdot 08$, while the autodilution method gave an A mean of $6 \cdot 23$ and a B mean of $6 \cdot 11$.

The $95 \%$ confidence limits for the standard method were $6.84 \pm 1.41$ and for the autodilution method $6 \cdot 18 \pm 1 \cdot 28$. The $F$ ratio for the two methods was 1.21 which was not significant.

\section{Discussion}

Two new methods for measuring folate activity are described. Both use a chloramphenicolresistant strain of $L$. case $i$ and a substrate containing $10 \mu \mathrm{g} / \mathrm{ml}$ of this antibiotic. The procedure eliminates the need for sterilization or aseptic addition (Herbert, 1966) and to date contaminants have not been observed during the 20-hour growth period required for the test. Chloramphenicol was chosen for several reasons. It is cheap and therefore does not greatly affect the cost of the test; it is stable and suppresses most of the contaminants encountered in this laboratory; and resistant forms of $L$. case $i$ are developed with relative ease without affecting the organism's response to folate.

It has been customary to use a young four to six-hour (David and Kelly, 1962) or six to eight-hour culture (Herbert, 1966) for the assay, but this makes it difficult to set up the tests until late afternoon. With manual setting up this was not a problem, because the inoculation was seldom made before this time. However, with the methods described, setting up time may be restricted to an hour or so where there are only 60 to 80 samples, but may extend to several hours when several hundred samples are to be set up, and the inoculum should be available early in the working day. For this reason the use of an overnight culture was examined, and results were fot found to differ significantly from those obtainęed using a four to six-hour culture. Inoculating the medium in bulk had several advantages: it gaves a better suspension of the organisms resulting in more even growth; and the autodilutor methō reduced the number of manipulations and greaty increased the speed of setting up.

The standards were prepared in a similar man $\overline{\overline{v e}}$ for both methods. They were sampled in the same way as the test samples, and reflected mare accurately the test conditions than those that have been prepared quite separately from $\overrightarrow{\mathrm{he}}$ preparation of the test samples.

Ascorbic acid was not added to the samp移s before being assayed, nor was it used when diluting the samples before assay in the Aus. Analyzer. It has been shown that ascorbic aeid adversely affects the assay of vitamin $B_{12}$ (Frost, Lapidus, Plaut, Scherfling, and Fricke, 1952; Waters and Mollin, 1963), and there are obviois advantages where samples were assayed for both vitamins.

No additional buffer was added, as the buffiring capacity of the medium was found to De satisfactory. Harper (1965) came to a simifar conclusion.

The medium described by Cooperman (19 ब) was examined to see if it could replace our standard medium. Growth compared unfavourably with that obtained using our standat medium prepared with enzymatic casein hydpolysate.

The Mecolab system has been modified to enable it to handle large numbers of samplegs. It has been fitted with a plate taking 40 serum samples at a time, and this gives it a tremendogis capacity over a normal working day. It is able set up tests in duplicate or triplicate as requibed and is also able to set up at a number of different dilutions. The system has the advantage tha duplicates by sophisticated instrumentation me semi-automated technique. There is no waste of reagents similar to that associated with systegls using continuous flow methods, and the unit $\mathrm{sis}$ extremely simple to operate. The instrument also be suitable for an automated vitamin $\overline{\mathbf{B}}_{2}$ assay.

The method using the autodilutor requires vety little equipment and is as fast as the fully autsmated system using the AutoAnalyzer. The settimg up is in fact faster, but measuring the growth is still rather tedious. This has been overcome some extent by the use of a colorimeter fitted with a flow cell.

The method using the AutoAnalyzer enab癄 the system to be used where long incubation times are required in a way that has not previoudy been described. Quite large coils of polytheghe tube can be used, provided care is taken to provide a balanced pressure at both ends of tube. Failure to balance the coil pressure 11 result in an unsatisfactory colorimeter flow. The 
preliminary dilution of the sample for the analyzer system makes it compatible with a similar system designed for the sasay of vitamin $B_{12}$.

We wish to thank Dr D. Curnow, head of the Department of Biochemistry, for allowing us to use his AutoAnalyzer; Dr M. Cohen, also of the Department of Biochemistry, for the statistical analysis, and Dr H. J. Woodliff, head of the Department of Haematology, for his continued advice and encouragement, Joyce Loebl and Co. very kindly made available their Mecolab automated equipment and Miss Graham Carter also gave invaluable assistance in setting up the AutoAnalyzer.

References

Baker, H., Herbert, V., Frank, O., Pasher, I., Hutner, S. H., Wasserman, L. R., and Sobotka, H. (1959). Clin. Chem., \& $5,275$.

Cooperman, J. M. (1967). Amer. J. clin. Nutr., 20, 1015.

Davis, R. E., and Kelly, A. (1962). Aust. J. exp. Biol. med-Sci., 40, 437.

Frost, D. V., Lapidus, M., Plaut, K. A., Scherfling, E., and Fricke, H. H. (1952). Science, 116, 119.

Harper, T. A. (1965). Nature (Lond.), 207, 947.

Herbert, V. (1961). J. clin. Invest., 40, 81.

Herbert, V. (1966). J. clin. Path., 19, 12.

Hoff brand, A. V., Newcombe, B. F. A., and Mollin, D. L.(1966). J. clin. Path., 19, 17.

Waters, A. H., and Mollin, D. L. (1961). J. clin. Path., 14, 33. Waters, A. H., and Mollin, D. L. (1963). Brit. J. Haemat., 9, 319.

\section{The November 1969 Issue}

\section{THE NOVEMBER 1969 ISSUE CONTAINS THE FOLLOWING PAPERS}

The Journal of Clinical Pathology-nine times a year!

Research and development N. H. MARTIN

Gram-negative bacilli in burns BRENDA DAVIS, H. A. LILLY, and E. J. L. LOWBURY

Gram-negative septicaemia during haemorrhage from an anastomotic ulcer J. D. WARD

Sensitivity of Gram-negative bacilli to ampicillin after six years' clinical usage B. SLOCOMBE and R. SUTHERLAND

Incidence of toxoplasmosis in women at a London hospital C. F. RUOSS and G. L. BOURNE

A simple quantitative and qualitative microbiological screening test for bacteriuria E. M. MACKAY-SCOLLAY

Isolation of a Coxsackie virus group B, type 5, from the heart of a fatal case of myocarditis in an adult MAURICE LONGSON, F. M. COLE, and DEREK DAVIES

Reaction pattern to three stresses-electroplexy, surgery, and myocardial infarction-of fibrinolysis and plasma fibrinogen R. CHAKRABARTI, E. D. HOCKING, and G. R. FEARNLEY

Disseminated fibrin thromboembolism among neonates dying more than $\mathbf{4 8}$ hours after birth J. F. BOYD

Effect of drugs on vitamin $B_{12}$ levels obtained using the Lactobacillus leichmanii method D. E. B. POWELL, J. H. THOMAS, A. R. MANDAL, and C. T. DIGNAM

Effect of sulphydryl inhibition on the uptake of transferrin-bound iron by reticulocytes J. FIELDING, SHIRLEY A. EDWARDS, and RICHARD RYALL

Plasma iron values in National Blood Transfusion Service donors E. A. FRENCH and PUSHPA K. SITLANI
Uncertainties in the determination of the 'cortisol-binding capacity' of plasma and their removal c. W. BURKE

Catecholamine metabolite excretion in spina bifida B. MCKIBBIN, L. O'GORMAN, and T. DUCKWORTH

Adsorption of ${ }^{59} \mathrm{Fe}$ on glassware and its effect on data deduced MARY D. SMITH and T. KERNAGHAN

Bone changes in polycythaemia vera and myelosclerosis B. E. ROBERTS, C. G. WOODS, D. W. MILES, and C. R. PATERSON

Culture of needle biopsies of the liver from patients with suspected hepatitis PATRICIA E. TAYLOR, A. J. ZUCKERMAN, and J. L. FARROW

Hepatic fluorescence in porphyria cutanea tarda studied in fine needle aspiration biopsy smears OVE LUNDVALL and LENNART ENERBÄCK

Use of activated charcoal in the radioimmunoassay of human growth hormone in plasma H. S. JACOBS

Bronchial carcinoma and hypercalcaemia

J. G. AZZOPARDI and R. S. WHITTAKER

Congenital mesonephric defects in male infants with muscoviscidosis J. R. OLSON and D. K. WEAVER

Use of soluble swabs in the diagnosis of bladder neoplasia P. A. TROTT, GRANT WILLIAMS, and P. W. ATTRIDGE

Technical methods

Storage of virus-infected tissue culture substrates for the detection of serum antibodies by immunofluorescence G. SANDER

Letters to the Editor

Book reviews

Notice

The Association of Clinical Pathologists: 83rd General Meeting

Index to Volume XXII

Contents

Copies are still available and may be obtained from the PUBLISHING MANAGER, BRITISH MEDICAL ASSOCIATION, TAVISTOCK SQUARE, W.C.1 price $21 \mathrm{~s}$. 